\title{
Computed tomography findings of postoperative complications in lung transplantation*,**
}

\author{
Achados tomográficos nas complicações \\ pós-operatórias do transplante pulmonar \\ Bruno Hochhegger, Klaus Loureiro Irion, Edson Marchiori, \\ Rodrigo Bello, José Moreira, José Jesus Camargo
}

\begin{abstract}
Due to the increasing number and improved survival of lung transplant recipients, radiologists should be aware of the imaging features of the postoperative complications that can occur in such patients. The early treatment of complications is important for the long-term survival of lung transplant recipients. Frequently, HRCT plays a central role in the investigation of such complications. Early recognition of the signs of complications allows treatment to be initiated earlier, which improves survival. The aim of this pictorial review was to demonstrate the CT scan appearance of pulmonary complications such as reperfusion edema, acute rejection, infection, pulmonary thromboembolism, chronic rejection, bronchiolitis obliterans syndrome, cryptogenic organizing pneumonia, posttransplant lymphoproliferative disorder, bronchial dehiscence and bronchial stenosis.
\end{abstract}

Keywords: Tomography, X-ray computed; Lung transplantation; Postoperative complications.

\section{Resumo}

Com o número cada vez maior e uma melhor sobrevida dos pacientes submetidos ao transplante pulmonar, os radiologistas devem estar cientes das diversas possibilidades de complicações associadas ao transplante de pulmão. 0 tratamento precoce das complicações é importante para a sobrevida a longo prazo dos receptores de transplante pulmonar. Com frequência, a TCAR desempenha um papel central na investigação de tais complicações. 0 reconhecimento precoce dos sinais de complicações proporciona um tratamento rápido e melhora a sobrevida. 0 objetivo desta revisão pictórica foi proporcionar uma visão sobre as complicações mais prevalentes na TC, tais como edema de reperfusão, rejeição aguda, infecção, tromboembolismo pulmonar, rejeição crônica, síndrome da bronquiolite obliterante, pneumonia em organização criptogênica, doença linfoproliferativa pós-transplante, deiscência brônquica e estenose brônquica

Descritores: Tomografia computadorizada por raios X; Transplante de pulmão; Complicações pós-operatórias.

Lung transplantation has become an established technique for the treatment of end-stage pulmonary diseases in adults. ${ }^{(1,2)}$ The number of transplantations performed annually and the number of centers performing lung transplantations continue to increase. ${ }^{(1,2)}$

Although single lung transplantation was previously more common, double lung transplantation is currently the preferred option for all patients with end-stage pulmonary disease, due to the better long-term survival of patients submitted to the latter procedure. ${ }^{(2,3)}$ Survival after lung transplantation has also greatly improved as a result of advances in surgical technique, careful harvesting/preservation of donor organs, improvements in immunosuppressive therapy and earlier recognition of complications with the use of various imaging techniques. The reported one-, five-, ten- and fifteen-year survival rates are 75\%, 50\%, 35\% and $25 \%$, respectively. ${ }^{(3,4)}$ The most common cause of mortality in the first 6 months is bacterial infection, which is thereafter supplanted by chronic graft dysfunction. ${ }^{(3)}$

The clinical and radiological manifestations of postoperative complications can be nonspe-

\footnotetext{
* Study carried out under the auspices of the Postgraduate Program in Respiratory Sciences of the Universidade Federal do Rio Grande do Sul - UFRGS, Federal University of Rio Grande do Sul - Porto Alegre, Brazil and of the Postgraduate Program in Radiological Sciences of the Universidade Federal do Rio de Janeiro - UFRJ, Federal University of Rio de Janeiro - Rio de Janeiro, Brazil. Correspondence to: Bruno Hochhegger. Rua João Alfredo, 558/301, Cidade Baixa, CEP 90050-230, Porto Alegre, RS, Brasil. Tel 5555 3286-4230. E-mail: brunorgs@mail.ufsm.br
}

Financial support: None.

Submitted: 28 October 2008. Accepted, after review: 20 January 2009.

**A versão completa em português deste artigo está disponivel em www.jornaldepneumologia.com.br 
cific and at times confusing. The aim of this paper was to describe the most common postoperative complications in adult recipients of lung transplants, based on a retrospective evaluation of cases at our institution and a review of literature. We have grouped the most prevalent complications by type: reperfusion edema; acute rejection; infections; pulmonary embolism and infarction; cryptogenic organizing pneumonia; chronic rejection (due to bronchiolitis obliterans syndrome); bronchial anastomosis complications (including bronchial dehiscence and stenosis); and post-transplant lymphoproliferative disorder. These can also be categorized temporally as follows: immediate complications (occurring within the first $24 \mathrm{~h}$ after transplantation), which are related to respiratory mechanics (e.g., pneumothorax); early complications (occurring within the first 2 postoperative months), which include reperfusion edema, acute rejection, infection, bronchial dehiscence and pulmonary thromboembolism; and late complications (occurring after postoperative month 2), which include chronic rejection (bronchiolitis obliterans syndrome), cryptogenic organizing pneumonia, post-transplant lymphoproliferative disorder and bronchial stenosis. ${ }^{(5)}$

\section{Reperfusion edema}

Reperfusion edema (ischemia-reperfusion injury) is noncardiogenic pulmonary edema that typically develops more than $24 \mathrm{~h}$ after transplantation, peaks in severity on postoperative day
4 and generally improves by the end of the first postoperative week. This condition also referred to as the pulmonary reimplantation response. The edema can persist for up to 6 months after transplantation. However, in most lung transplant recipients, it will have resolved completely by postoperative month 2.(6) Although chest $\mathrm{X}$-ray is the most common form of radiological investigation, CT scans can provide valuable additional information (Figure 1). At peak severity, reperfusion edema appears, in the upper, middle and lower lung zones, as reticular interstitial disease in 19\%, 33\% and 34\% of cases, respectively, or as airspace disease in 31\%, 61\% and $57 \%$ of cases, respectively. ${ }^{(7)}$ Reperfusion edema has been reported to be asymmetric in nearly $20 \%$ of patients undergoing double lung transplantation. ${ }^{(7)}$ The CT features are nonspecific and can include perihilar ground-glass opacities, peribronchial/perivascular thickening, pleural effusion (Figure 1) and reticular interstitial/airspace opacities located predominantly in the middle and lower lung lobes. ${ }^{(7)}$

\section{Acute rejection}

Acute rejection after transplantation is a common occurrence. Nearly 95\% of patients present at least two episodes within the first month after surgery. Histologically, acute rejection is characterized by predominantly lymphocytic perivascular infiltrate, with or without bronchiolar involvement. ${ }^{(8)}$ Symptoms are generally nonspecific, including low-grade

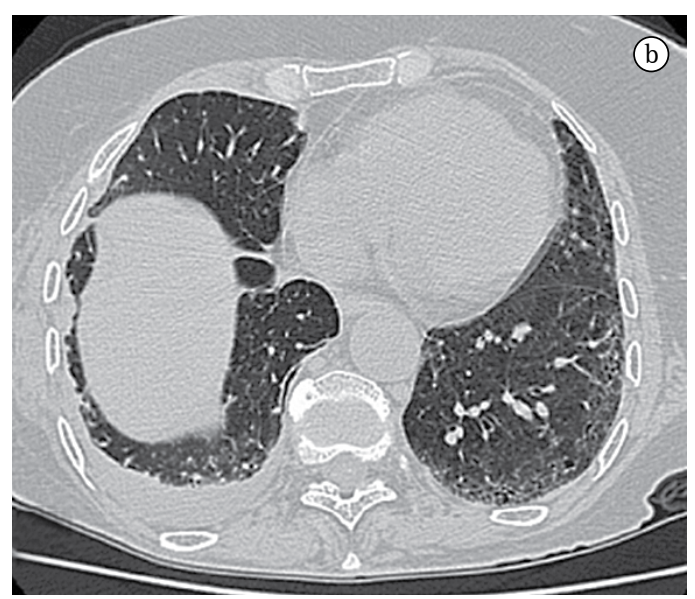

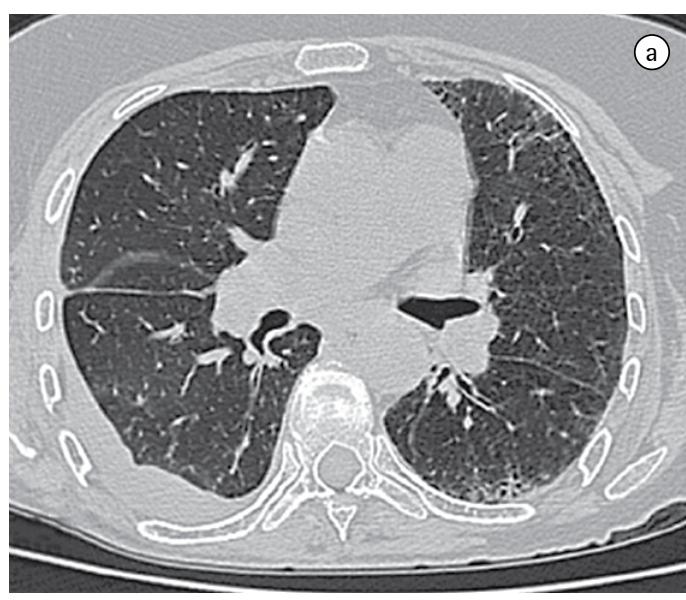

Figure 1 - Reperfusion edema in a recipient of a double lung transplant due to emphysema. Images on postoperative day 3: HRCT scans of the chest demonstrating right pleural effusion with peribronchial/ perivascular and interlobular septal thickening in the lower zones of the graft lungs; the heart is normal in size, shape and position. By postoperative week 2, the lungs were unremarkable. 
fever, breathlessness and fatigue. Most patients experience at least one episode of acute rejection within the first 3 weeks and remain at high risk for this complication for the first 100 days after transplantation. ${ }^{(5)}$ Chest X-ray findings are normal in up to $50 \%$ of cases. ${ }^{(6)}$ The most common findings are perihilar and lower-lobe opacities, as well as interlobular septal thickening and pleural effusion (Figure 2). ${ }^{(9)}$ The HRCT features are relatively nonspecific and include ground-glass opacities (often with basal distribution), peribronchial cuffing, septal thickening (interlobular and intralobular) and new or more extensive pleural effusion. ${ }^{(10)}$ This complication can be almost completely excluded if there are no ground-glass opacities. ${ }^{(9)}$ Acute rejection is treated with intravenous corticosteroids and typically responds quite well after $24 \mathrm{~h}$ of this treatment. A dramatic reduction in abnormal radiological features after $48 \mathrm{~h}$ of intravenous administration of methylprednisolone is indicative of a diagnosis of acute rejection..$^{(9,10)}$

\section{Infections}

Pulmonary infections, which constitute a leading cause of morbidity and mortality, can occur at any time after transplantation. ${ }^{(3)}$ The direct communication between the transplanted lung and the atmosphere facilitates infection. This is compounded by impaired mucociliary clearance and failure of the cough reflex. ${ }^{(11)}$ The majority (65\%) of transplant recipients develop infectious complications, 30\% of which are extrapulmonary. ${ }^{(5)}$ Most such infections involve the transplanted lung. ${ }^{(12)}$ Bacteria and fungi are major causes of infection within the first postoperative month, whereas viral infections are more prevalent in postoperative months 2 and 3. ${ }^{(6)}$

Severe bacterial pneumonia accounts for more than $60 \%$ of post-transplant infections and is typically caused by Staphylococcus aureus, enterobacteriaceae, Pseudomonas aeruginosa or other gram-negative organisms. ${ }^{(12)}$ Although the incidence of bacterial pneumonia is highest in the first month after transplantation, bacterial pneumonia continues to be a potential major infectious complication throughout the life of the patient. ${ }^{(12,13)}$ The incidence of serious bacterial pneumonia in the immediate postoperative period after lung transplantation has been reduced by the routine prophylactic use of broad-spectrum antibiotics. ${ }^{(13)}$ In lung transplant recipients, the radiological manifestations of bacterial pneumonia, which include lobar or diffuse consolidation, cavitations and lung nodules, are similar to those seen in other hospitalized patients with bacterial pneumonia. ${ }^{(13)} \mathrm{In}$ this context, CT might be helpful in confirming the presence of subtle radiographic abnormalities, thereby directing the clinician to the most appropriate lobe at bronchoscopy. For some infections, the CT appearance can suggest a

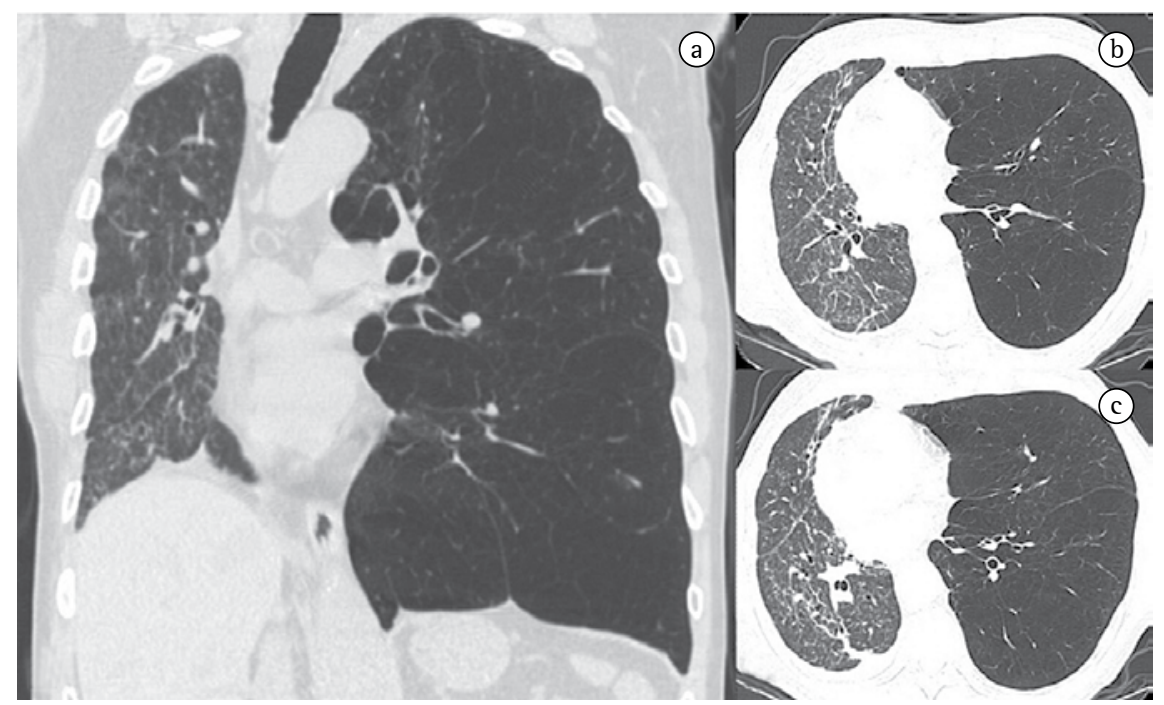

Figure 2 - Acute rejection in a recipient of a single lung transplant due to emphysema. Images at postoperative week 2: (a) coronal multidetector CT reconstruction showing areas of ground-glass opacity accompanied by linear atelectasis; and (b/c) axial HRCT slices better demonstrating the interlobular septal thickening. 

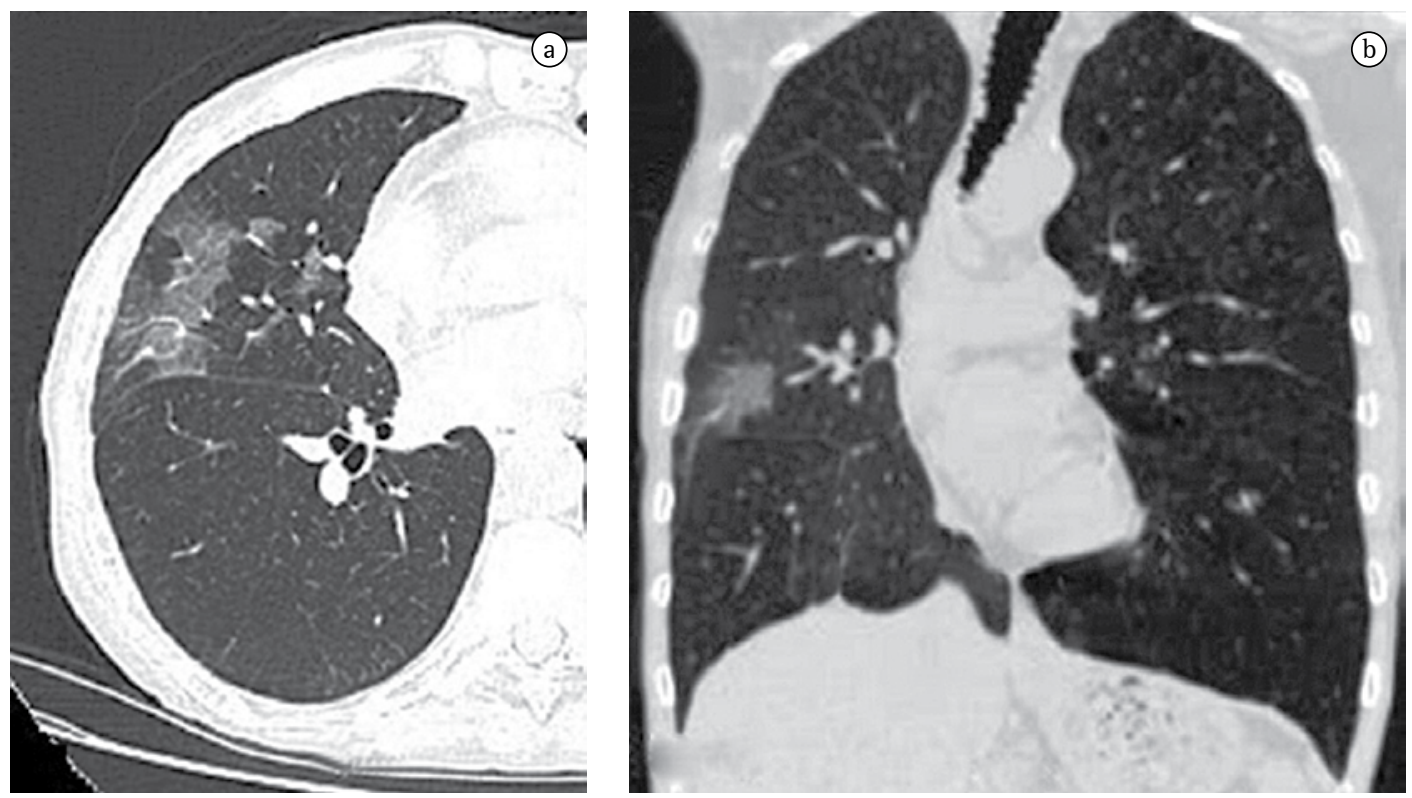

Figure 3 - CMV infection in a recipient of a single lung transplant due to emphysema, presenting dyspnea, fever and leukopenia on postoperative day 36. Images: (a) axial HRCT scan of the chest demonstrating groundglass opacities in the middle lobe accompanied by mild interlobular septal thickening and sparse areas of acinar consolidation; and (b) coronal reconstruction showing that the findings are located in the middle lobe only. The diagnosis was confirmed by biopsy.

specific infectious agent. ${ }^{(5)}$ The following are the most common CT findings in cases of infection after lung transplantation: atelectasis; bronchocentric opacities; subsegmental, segmental or lobar airspace consolidation; branching nodular and linear opacities ("tree-in-bud" appearance); interlobular septal thickening; and pleural effusion. ${ }^{(13-15)}$

Opportunistic infection occurs in 34-59\% of lung transplant recipients. ${ }^{(13)}$ Unfortunately, in patients with new opportunistic pneu- monia, chest X-ray findings can be normal, and abnormal findings, when present, are often nonspecific. (11) Cytomegalovirus (CMV) is the most common opportunistic infection among such patients. ${ }^{(14)}$ The incidence of CMV infection peaks between 1 and 2 months after transplantation, most cases occurring between postoperative months 1 and $12 .{ }^{(11,14)}$ Infection with CMV can be primary and secondary. Primary infection occurs in over 90\% of CMV seronegative patients receiving a CMV seropositive
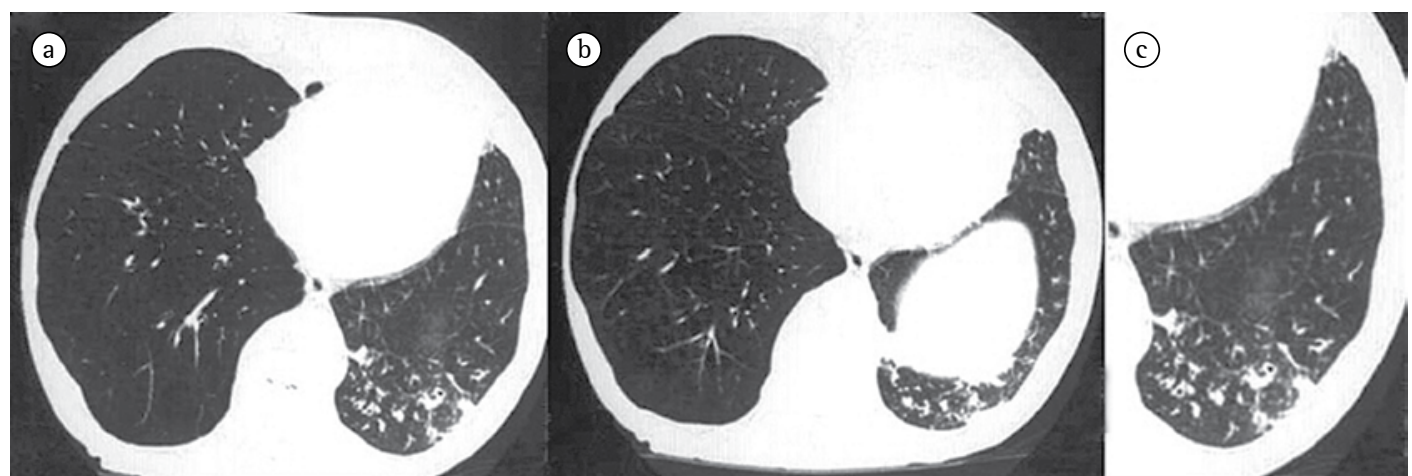

Figure 4 - Aspergillosis in a recipient of a single lung transplant due to emphysema, presenting dyspnea and fever at 3 months after transplantation. Images: (a/b) HRCT scans showing multifocal nodular and mass-like regions in the lower zones of the transplanted lung; (c) HRCT scan showing a mass-like region surrounded by ground-glass opacity (halo sign). 

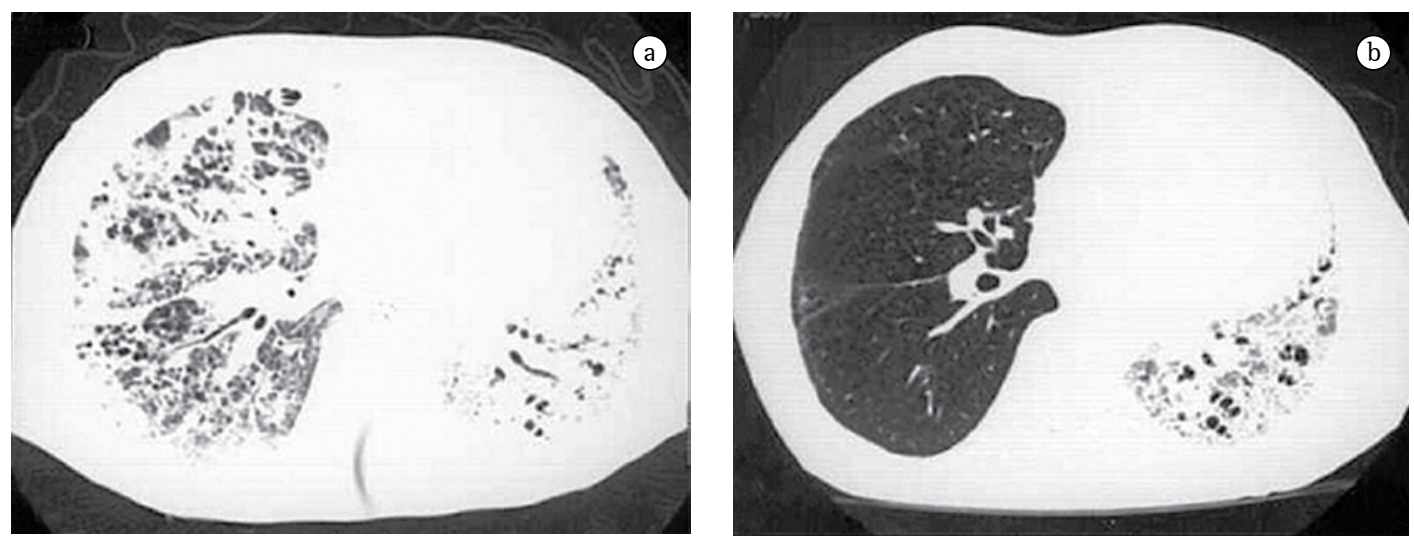

Figure $\mathbf{5}$ - Cryptogenic organizing pneumonia in a recipient of a single lung transplant due to idiopathic interstitial pneumonia. Images: (a) HRCT scan at 4 months after transplantation showing airspace consolidation, reticular opacities, bronchiectasis and lung volume loss; and (b) HRCT scan after corticosteroid treatment.

donor lung and becomes severe in 50-60\% of such cases. ${ }^{(11)}$ Secondary infection results from exposure to a different CMV strain or from reactivation of a latent infection in the recipient and is usually less severe than is primary infection. ${ }^{(11)}$ Clinical manifestations of CMV infection include dyspnea, fever, malaise and leukopenia, although many patients with histologically proven CMV pneumonia are asymptomatic. ${ }^{(15)} \mathrm{A}$ diagnosis of CMV pneumonia is typically confirmed only after bronchoalveolar lavage and transbronchial biopsy. The radiologic manifestations of CMV pneumonia include, as shown in Figure 3, ground-glass opacities, interlobular septal thickening and consolidation, as well as diffuse reticular or reticulonodular opacities, nodules and small areas of effusion. ${ }^{(14)}$ In lung trans- plant recipients with active CMV infection, chest X-ray findings can be normal, ${ }^{(11)}$ CT scans better depicting the radiological manifestations of the infection, which almost exclusively affects the allograft. The most common CT manifestations are ground-glass opacities, tree-in-bud opacities, airspace consolidation, nodules, interlobular septal thickening, pleural effusions, thickened/ enlarged pleura and bronchiectasis. ${ }^{(11-15)}$ Other common viral pulmonary pathogens affecting this population include herpes simplex virus, adenovirus and respiratory syncytial virus. ${ }^{(11)}$

ln lung transplant recipients, fungal pneumonia, which is typically caused by Aspergillus spp. or Candida spp., is less common than is CMV pneumonia but is associated with higher mortality. ${ }^{(11,16,17)}$ Fungal pneumonia most often
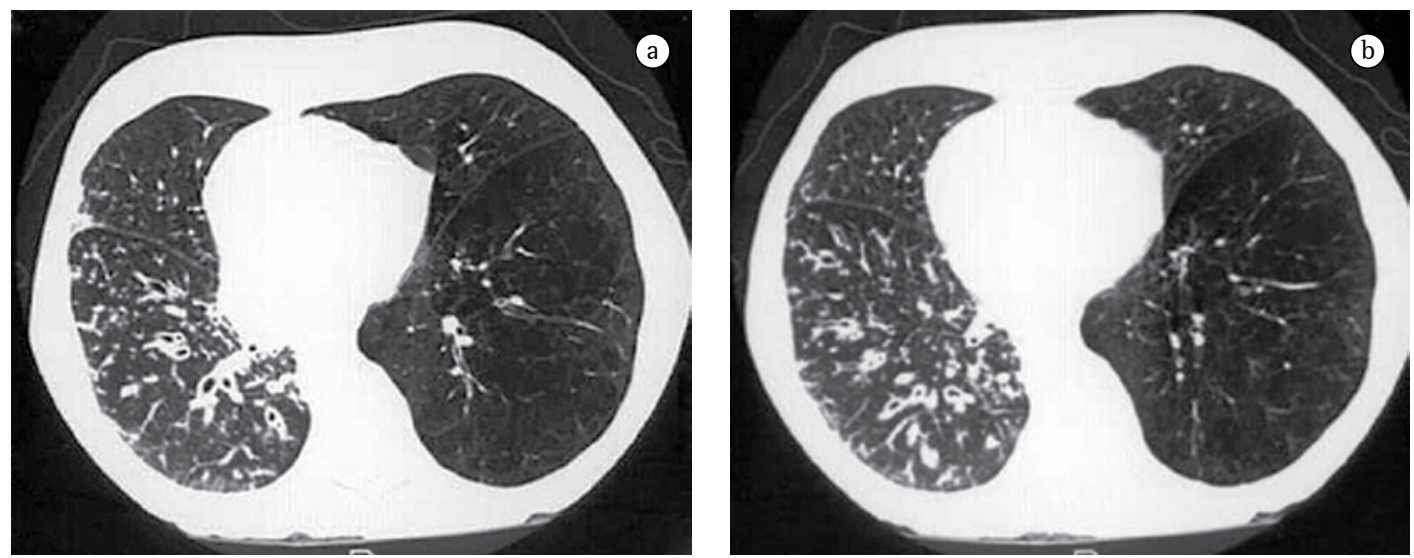

Figure 6 - Chronic rejection in a recipient of a single lung transplant due to emphysema, presenting, at postoperative month 15, a decline in $\mathrm{FEV}_{1}$ in relation to the postoperative baseline value. Images: (a/b) HRCT scans showing bronchiectasis, bronchial wall thickening, nodular and linear branching opacities, interlobular septal thickening and peribronchovascular infiltrates. 
occurs within the first 2 months after transplantation. ${ }^{(11)}$ Infection with Aspergillus spp. can present either as an indolent pneumonia or as a fulminant invasive infection with systemic dissemination. ${ }^{(16,17)}$ Aspergillus infection can also cause ulcerative tracheobronchitis that is often radiographically occult and can lead to anastomotic dehiscence. ${ }^{(11,17)}$ Although Candida spp. frequently colonize the airways, invasive pulmonary infection is rare. ${ }^{(11)}$ Fungal anastomotic infection or pneumonia is suspected on the basis of positive smears/cultures of bronchoalveolar lavage samples. However, since these organisms can colonize the donor lung, definitive diagnosis of invasive fungal infection might require transbronchial biopsy. ${ }^{(11)}$ Typical features on HRCT images include the following: focal nodular and mass-like regions of consolidation; cavitation; nodules (solitary or multiple) with a surrounding rim of ground-glass opacity, referred to as the "halo" sign (Figure 4); and pleural thickening. ${ }^{(16,17)}$

\section{Pulmonary embolism and infarction}

In lung transplant recipients, pulmonary thromboembolic events tend to occur within the first 4 months after transplantation. ${ }^{(18)}$ The incidence of such events has been reported to be $27 \%{ }^{(18)}$ Radiographic findings are relatively nonspecific and indirect; the most common being pleural effusion. Pulmonary CT angiography is the diagnostic method of choice in suspected cases of pulmonary thromboembolic disease. The CT findings include central arterial filling defects, localized arterial distention and abrupt arterial occlusion. Nonvascular findings include wedge-shaped consolidation, "mosaic hypoperfusion" (mosaic oligemia), atelectasis and pleural effusion. ${ }^{(18)}$

\section{Cryptogenic organizing pneumonia}

The prevalence of cryptogenic organizing pneumonia among lung transplant recipients is $10-28 \%{ }^{(19)}$ This clinicopathologic syndromecharacterized clinically by subacute or chronic respiratory illness and pathologically by polypoid masses of granulation tissue in the lumen of small airways, alveolar ducts, and some alveoli-is associated with a variable degree of interstitial and airspace infiltration by mononuclear cells and foamy macrophages. ${ }^{(19)}$ An HRCT scan often reveals airspace consolidation, ground-glass opacities, nodular or mass-like consolidation and linear or reticular opacities (Figure 5). Additional findings include bronchiectasis, bronchiolectasis, fibrosis, lung volume loss and air trapping. ${ }^{(19)}$

\section{Chronic rejection}

Bronchiolitis obliterans syndrome (BOS) is defined as a clinical syndrome of progressive, irreversible airway obstruction in the pulmonary allograft caused by the presence of constrictive (obliterative) bronchiolitis, ${ }^{(5)}$ which results from eosinophilic fibrous scarring of the small airways. The term BOS is used to describe less specific graft dysfunction featuring physiologic airflow obstruction and a decline in FEV ${ }_{1}$ in rela-

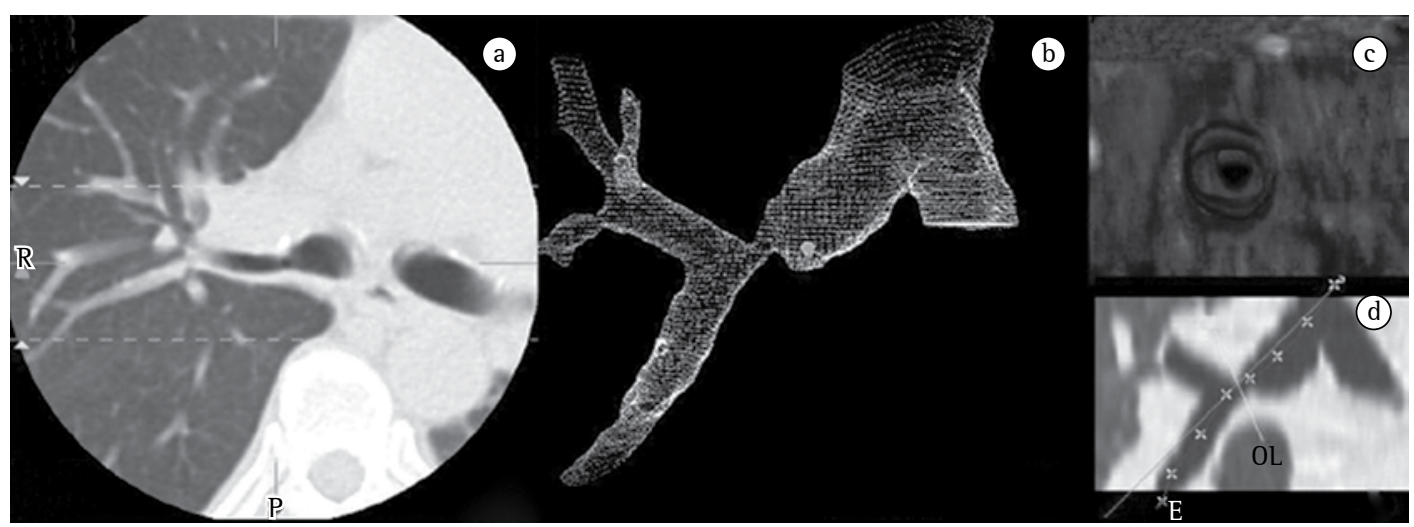

Figure 7 - Bronchial stenosis in a recipient of a single lung transplant due to emphysema. Images at 5 months after transplantation: (a) axial HRCT scan with focused field of view showing stenosis of the right main bronchus; (b) volume rendering showing the evident right stenosis; (c) virtual endoscopy of the stenosis; and (d) multiplanar reconstruction. 
tion to the postoperative baseline value. Chronic allograft rejection remains the principal late complication of lung transplantation; affecting at least $50 \%$ of recipients within 5 years, irrespective of specific risk factors. ${ }^{(20)}$ The radiographic manifestations of BOS are nonspecific and include subsegmental atelectasis, decreased peripheral vascular markings and peribronchial cuffing, as well as reduced or increased lung volumes. ${ }^{(20)}$ The CT findings of chronic rejection include, as shown in Figure 6, bronchial wall thickening, nodular/linear branching opacities, interlobular septal thickening and peribronchovascular infiltrates, as well as bronchiectasis, air trapping, regional volume expansion/contraction, mosaic lung attenuation and decreased/ distorted peripheral arteries. ${ }^{(20)}$ Dilated bronchi and bronchiectasis, as well as air trapping (which is pronounced in the lower lobes), are better demonstrated through HRCT imaging studies.

\section{Bronchial anastomosis complications}

Complications at the bronchial anastomosis occur in approximately 15\% of lung transplant recipients. Such complications include bronchial stenosis (Figure 7), dehiscence, bronchomalacia, exophytic granulation tissue formation and anastomotic infection. ${ }^{(5)}$ In $50 \%$ of cases, balloon dilatation or bronchial stent placement is required. ${ }^{(5)}$ Donor bronchus ischemia caused by disruption of the native bronchial circulation is a key factor underlying airway complications. ${ }^{(6)}$ Pulmonary infection is an additional exacerbating factor. In the early postoperative period, ischemia can result in bronchial dehiscence or fistula. ${ }^{(5)}$ Bronchial dehiscence typically occurs within the first month after lung transplantation. Anastomotic dehiscence is identified based on CT findings of bronchial wall defect, bronchial narrowing (fixed or dynamic), bronchial wall irregularity or extraluminal air. ${ }^{(21)}$ Multiplanar and three-dimensional CT reconstructions provide precise information regarding the extent of these complications. Indirect features of bronchial anastomosis complication include air leak, manifesting as pneumothorax, pneumomediastinum or stenosis and resulting in poor allograft expansion, as evidenced by ipsilateral lung volume loss. ${ }^{(21)}$ Unfortunately, CT does not reliably depict mucosal necrosis, which is the earliest sign and a useful predictor of dehiscence. When CT findings are negative in patients presenting clinical or indirect features, direct bronchoscopy should be performed in order to identify possible mucosal necrosis. ${ }^{(21)}$ Bronchial anastomotic stenosis and bronchomalacia are usually seen within the first 4 months after lung transplantation. However, the overall incidence of airway complications is decreasing due to improvements in preservation methods, surgical techniques and immunosuppressive therapy. Bronchial narrowing due to stricture, with significant stenosis, defined as a reduction of more than $50 \%$ in bronchial diameter, ${ }^{(21)}$ can be seen on CT scans. In cases of bronchomalacia, airway collapse or transient narrowing of the anastomosis (or of other airway segments) can be detected through expiratory CT or dynamic CT during respiration. ${ }^{211}$ Bronchomalacia can also be detected at bronchoscopy during spontaneous breathing. ${ }^{(21)}$

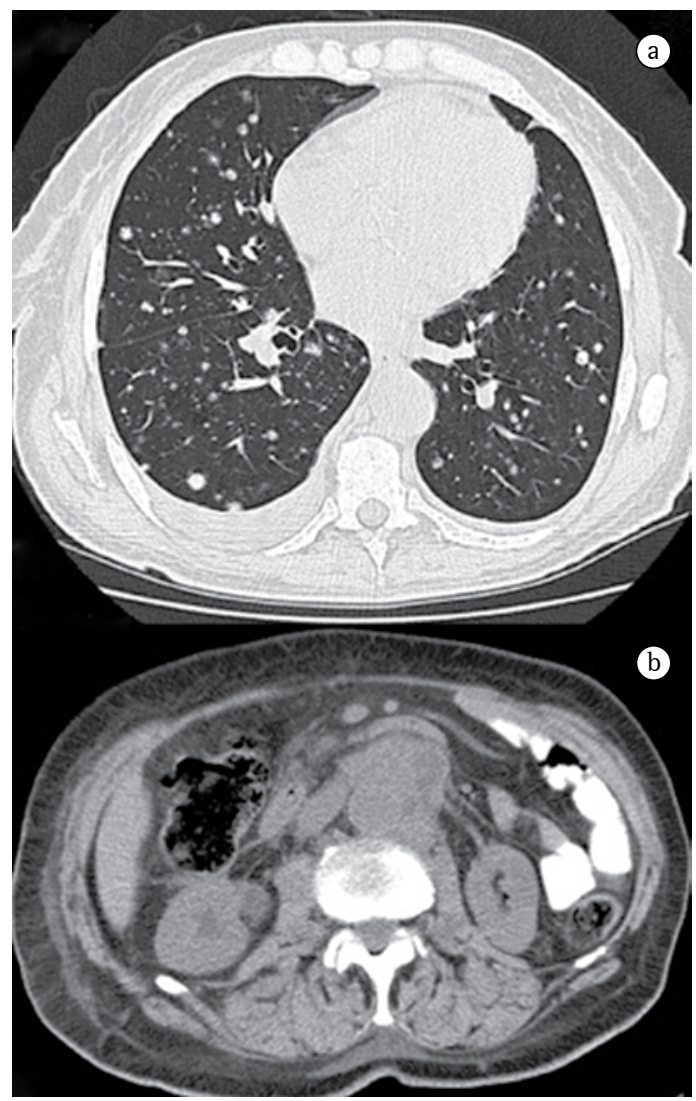

Figure 8 - Lymphoproliferative disorder in a recipient of a double lung transplant. Images at 8 months after transplantation: (a) axial HRCT scan showing multiple bilateral pulmonary nodules and right pleural effusion; and (b) axial CT scan of the abdomen showing retroperitoneal lymphadenomegaly. 


\section{Post-transplant lymphoproliferative disorder}

Post-transplant lymphoproliferative disorder (PTLD) is an uncommon but serious complication of immunosuppressive therapy following solid organ transplantation. It has been shown to occur in up to 5\% of patients, depending on the type of organ transplanted, as well as on the type and duration of immunosuppressive therapy.(22) it is much more common for PTLD to occur after lung transplantation than after liver or kidney transplantation. ${ }^{(22)}$ The presentation of PTLD consists of a spectrum of lymphoid neoplasms that are primarily of B-cell origin. ${ }^{(22)}$ Approximately 90\% of patients with PTLD are infected with EpsteinBarr virus. Seronegative status for Epstein-Barr virus prior to transplantation is thought to be a major risk factor for the development of PTLD, the incidence of which varies from $2.8 \%$ to $6.1 \%$ at 1 year after transplantation. ${ }^{(22)}$ When the disorder appears in the early postoperative period, it tends to follow a benign course and responds favorably to antiviral therapy and a reduction of immunosuppression. Late disease, which can develop more than 1 year after transplantation and is predominantly accompanied by extrathoracic involvement, is most often treated with chemotherapy and irradiation. ${ }^{(22)}$ The radiographic manifestations of PTLD include multiple pulmonary nodules, predominantly in the peripheral and basal zones (Figure 8). Other less common patterns of involvement include air space consolidation, mediastinal/ hilar lymphadenopathy, masses (in the pleura or chest wall), effusion (pericardial or pleural) and thymus enlargement. ${ }^{(22)}$

\section{Final considerations}

In summary, the most common and significant complications of lung transplantation are reperfusion edema, acute rejection, chronic rejection, CMV infection and cryptogenic organizing pneumonia, as well as dehiscence or stenosis of the bronchial anastomosis. In lung transplant recipients, a finding of pulmonary infiltrates, mediastinal shift, pleural effusion, pneumothorax or pneumomediastinum demands further investigation.

\section{References}

1. Unilateral lung transplantation for pulmonary fibrosis. Toronto Lung Transplant Group. N Engl J Med. 1986;314(18):1140-5.
2. Hadjiliadis D, Chaparro C, Gutierrez C, Steele MP, Singer LG, Davis RD, et al. Impact of lung transplant operation on bronchiolitis obliterans syndrome in patients with chronic obstructive pulmonary disease. Am J Transplant. 2006;6(1):183-9.

3. de Perrot M, Chaparro C, McRae K, Waddell TK, Hadjiliadis D, Singer LG, et al. Twenty-year experience of lung transplantation at a single center: Influence of recipient diagnosis on long-term survival. J Thorac Cardiovasc Surg. 2004;127(5):1493-501.

4. Trulock EP, Edwards LB, Taylor DO, Boucek MM, Mohacsi PJ, Keck BM, et al. The Registry of the International Society for Heart and Lung Transplantation: Twentieth Official adult lung and heart-lung transplant report-2003. J Heart Lung Transplant. 2003;22(6):625-35.

5. Ward S, Müller NL. Pulmonary complications following lung transplantation. Clin Radiol. 2000;55(5):332-9.

6. Krishnam MS, Suh RD, Tomasian A, Goldin JG, Lai C, Brown K, et al. Postoperative complications of lung transplantation: radiologic findings along a time continuum. Radiographics. 2007;27(4):957-74.

7. Kundu S, Herman SJ, Winton TL. Reperfusion edema after lung transplantation: radiographic manifestations. Radiology. 1998;206(1):75-80.

8. Yousem S. A perspective on the Revised Working Formulation for the grading of lung allograft rejection. Transplant Proc. 1996;28(1):477-9.

9. King-Biggs MB. Acute pulmonary allograft rejection. Mechanisms, diagnosis, and management. Clin Chest Med. 1997;18(2):301-10.

10. Loubeyre P, Revel D, Delignette A, Loire R, Mornex JF. High-resolution computed tomographic findings associated with histologically diagnosed acute lung rejection in heart-lung transplant recipients. Chest. 1995;107(1):132-8.

11. Erasmus JJ, McAdams HP, Tapson VF, Murray JG, Davis RD. Radiologic issues in lung transplantation for end-stage pulmonary disease. AJR Am J Roentgenol. 1997;169(1):69-78.

12. Medina LS, Siegel MJ, Glazer HS, Anderson DJ, Semenkovich J, Bejarano PA, et al. Diagnosis of pulmonary complications associated with lung transplantation in children: value of CT vs histopathologic studies. AJR Am J Roentgenol. 1994;162(4):969-74.

13. Dauber JH, Paradis IL, Dummer JS. Infectious complications in pulmonary allograft recipients. Clin Chest Med. 1990;11(2):291-308.

14. Shreeniwas R, Schulman LL, Berkmen YM, McGregor CC, Austin JH. Opportunistic bronchopulmonary infections after lung transplantation: clinical and radiographic findings. Radiology. 1996;200(2):349-56.

15. Anderson DC. Role of the imaging specialist in the detection of opportunistic infection after lung transplantation: are we out of the loop? Radiology. 1996;200(2):325-6.

16. Kanj SS, Welty-Wolf K, Madden J, Tapson V, Baz MA, Davis RD, et al. Fungal infections in lung and heart-lung transplant recipients. Report of 9 cases and review of the literature. Medicine (Baltimore). 1996;75(3):142-56.

17. Guillemain R, Lavarde V, Amrein C, Chevalier P, Guinvarc'h A, Glotz D. Invasive aspergillosis after transplantation. Transplant Proc. 1995;27(1):1307-9.

18. Burns KE, lacono AT. Pulmonary embolism on postmortem examination: an under-recognized 
complication in lung-transplant recipients? Transplantation. 2004;77(5):692-8.

19. Arakawa H, Kurihara $\mathrm{Y}$, Niimi H, Nakajima $\mathrm{Y}$, Johkoh T, Nakamura H. Bronchiolitis obliterans with organizing pneumonia versus chronic eosinophilic pneumonia: high-resolution CT findings in 81 patients. AJR Am J Roentgenol. 2001;176(4):1053-8.

20. Skeens JL, Fuhrman CR, Yousem SA. Bronchiolitis obliterans in heart-lung transplantation patients: radiologic findings in 11 patients. AJR Am J Roentgenol. 1989;153(2):253-6.
21. Semenkovich JW, Glazer HS, Anderson DC, Arcidi JM Jr, Cooper JD, Patterson GA. Bronchial dehiscence in lung transplantation: CT evaluation. Radiology. 1995; 194(1):205-8.

22. Scarsbrook AF, Warakaulle DR, Dattani M, Traill Z. Post-transplantation lymphoproliferative disorder: the spectrum of imaging appearances. Clin Radiol. 2005;60(1):47-55.

\section{About the authors}

\section{Bruno Hochhegger}

Resident. Santa Casa Sisters of Mercy Hospital Complex, Porto Alegre, Brazil.

\section{Klaus Loureiro Irion}

Consultant Radiologist. The Cardiothoracic Centre NHS Trust and The Royal Liverpool and Broadgreen University Hospitals, Liverpool, England.

\section{Edson Marchiori}

Professor of Radiology. Fluminense Federal University, Niterói, Brazil.

\section{Rodrigo Bello}

Radiologist. Santa Casa Sisters of Mercy Hospital Complex, Porto Alegre, Brazil.

\section{José Moreira}

Full Professor of Pulmonology. Universidade Federal do Rio Grande do Sul - UFRGS, Federal University of Rio Grande do Sul - Porto Alegre, Brazil.

\section{José Jesus Camargo}

Physician. Santa Casa Sisters of Mercy Hospital Complex, Porto Alegre, Brazil. 